\title{
Exclusivity, Externalities \& Easements: Dynamic Spectrum Access and Coasean Bargaining
}

\author{
Timothy K. Forde \& Linda E. Doyle \\ Centre for Telecommunications Value-chain Research (CTVR), \\ Trinity College, University of Dublin, Ireland. \\ timforde@mee.tcd.ie, ledoyle@tcd.ie
}

\begin{abstract}
This paper explores the possibility of realising Coasean bargains to remove the presence of externalities in a libertarian system of exclusive spectrum rights through the creation of various economically motivated easements. We advocate that dynamic spectrum access (DSA) techniques can be used to enable rights holders reduce or eliminate the effects of externalities through local bargaining.

Many of the objections to the promotion of marketbased exclusive-rights assignment systems concern the ability of rights holders to enforce their spectrum rights, so as to extract maximal value. In an increasingly fragmented and less-regulated spectrum landscape, there will be an inevitable chafing of rights at the boundaries between the users of neighbouring blocks of spectrum; the spectral activities of one network may impinge on the ability of a neighbouring network to extract maximum value from its exclusively assigned spectrum.

Nonetheless, it is argued that it is possible to reduce, or eliminate, the existence of such externalities through the adjustment and exchange of rights through valueextraction-focussed bargaining. In essence, this represents a shift from a mindset of unilaterally enforcing rights to one of mutual remediation of any encroachment. Such an approach may offer a non-Pigouvian remedy to both the under-utilisation and over-utilisation of packages of exclusive rights to spectrum, allowing neighbours to find a tolerable level (a balance) of interference. This paper posits that DSA techniques will have a key role to play in the development of new DSA-based Coasean bargains which will be necessary to address a variety of coexistence issues that will arise between systems operating in neighbouring blocks of exclusively assigned spectrum.
\end{abstract}

\section{INTRODUCTION}

Dynamic spectrum access (DSA) networks offer the potential for co-existing operators to work cheek-byjowl in the spectrum usage continuum. There is ongoing investigation of unlicensed underlay users, easement users and opportunistic unlicensed users. The ongoing development of these technologies continues to demon- strate the ability of DSA-enabled networks to improve the efficiency of spectral usage. Such frequency agile networks may be used to opportunistically exploit white space in otherwise exclusively licensed bands [1]. Dynamic spectrum access techniques enable radios and networks to automatically sense the environment, using methods such as energy detectors, feature detectors and distributed spectrum sensing techniques [2], [3], and respond dynamically by adapting communication parameters to leverage and use the available radio and network resources.

The principles and techniques used in overlay/underlay networks demonstrate that coexistence, cooperation and competition is possible in a very fluid and fragmented radio environment. The regulatory and technical space for Primary users, i.e. licensees, and Secondary users, i.e. unlicensed users or those users licensed by the primary-licensee, is emerging. The FCC's notice [4] regarding the promotion of secondary markets for spectrum sets out a regulatory space for the use of DSA techniques in these Primary/Secondary and Secondary/Secondary scenarios.

While the spectrum-sensing and spectrum-shaping aspects of DSA are very focussed on exploiting free or non-exclusive spectrum, there is no reason, other than lack of regulatory clearance, why such techniques cannot be used to improve Primary/Primary interactions. From a technology perspective, there is no reason why DSA techniques cannot be sanctioned to improve coexistence, cooperation and competition between Primary users at the edges of their exclusive spectrum domains.

So, the contributions in this paper are motivated by a vision of a more liberal exclusive-use spectrum domain which can be exploited by increasingly reconfigurable, adaptive and disaggregated wireless networks [5]; a domain that encourages a more efficient distribution of spectrum and a better fit between the communication application and the underlying spectrum it uses; as 
envisioned by Coase [6]. Exclusive property-like rights, which include guarantees of exclusive access to spectrum coupled with flexibility regarding the technologies and services deployed, will likely form the basis of any liquid and competitive spectrum trading market [7]. Doyle [8], in a companion paper to this paper explores more general issues pertaining to the development of such a liberalised market.

However, even though the continuum of spectrum could be carved up from a legal and economic standpoint, radios will not always respect legal boundaries in an ideal manner. And to many, this is the crux of the proposal - aside from differing public-policy perspectives which are for political determination. Simply put, radio activity in one network may have an effect on the spectral activity in an neighbouring network - reducing the capacity and potential profitability of the network. While heretofore the command-and-control system enforced guard-bands between perceived highvalue users and made block allocations based on an economic value analysis approach [9], a liberalized marketbased assignment system would let the market decide on such matters. In such an idealised system, the market would lead to an efficient allocation of rights among the various market participants. The need for guard band identification and specification, for economic analysis of viable regions, etc. would be for the market to decide. The market would self-grade, self-allocate, e.g. high-end customers would demand a high-end service using highend technology in the most suitable (high-cost) spectrum.

In the rest of this paper we explore the possibility of realising Coasean bargains to remove the presence of externalities in a libertarian system of exclusive spectrum rights through the creation of various economically motivated easements. In the next section we discuss what interference means to the creation of a competitive marketbased, property-rights system. In Section III we discuss the rationale for Coasean bargaining in the spectrum domain. In Section IV we discuss some criticisms of the Coasean approach and discuss whether DSA techniques can reduce transaction costs. In Sections VI and VI$\mathrm{C}$ we look the ways in which flexible spectrum rights enable a variety of Coasean arrangements to take place and we also introduce the concept of Coasean bargaining for opportunistic spectrum users.

\section{INTERFERENCE}

The existence of radio interference, has both positive and negative connotations - admittedly, overwhelmingly negative. However, as Hazlett has noted [10], "Rational rules require that each dollop of interference occur where the benefits of the activity causing the conflict exceed the damages that result". From such a perspective, conflicts, i.e. interference, may be seen as a positive indicator of productive airwave use. As the rights of neighbouring users are exploited to, and beyond, the legal maxima indicated in the license, the tension at the boundaries of neighbouring rights holders increases. There is a tension between dead spectrum and over-utilised spectrum. The current allocation system cannot be labeled a success from a spectral efficiency perspective when measurements of urban-area spectrum usage in the Washington, D.C. and New York City areas have shown that about $60 \%$ of the prime sub-3 GHz spectrum goes unused [11]. Ensuring that the balance between dead-spectrum and interference-chaos is tilted in favour of the most technologically and economically efficient use of the spectrum means that bogeyman of interference chaos must be faced down by DSA solutions.

Hatfield et al. [12] have raised the question of the spillover effects of radio propagation, i.e. interference, as a key obstacle to the enforcement of a propertyrights spectrum regime. Hatfield uses the example of AM broadcast stations to elucidate the difficulties of constraining the geographical spread of such radio signals from summer to winter, between night and day. However, in the target range of fairly desirable and fungible frequencies [13], from $300 \mathrm{MHz}$ to $3 \mathrm{GHz}$, these effects of are less pronounced and more manageable. Nonetheless, they do exist and Hatfield considers the issue of co-channel interference to be the Achilles' heel of the property rights model. Melody [14] also repudiates the notion of a viable market of privately transferable rights based on the 'probabilistic nature of emission patterns' and the 'inherent market rigidities' (unexplained in the text) which would mitigate against any claimed allocative efficiency benefits accruing from a market-oriented approach. It is the purpose of dynamic spectrum access and management techniques, regardless of the regulatory context, to address (and solve) the 'probabilistic nature of emission patterns' which is held up as the primary technical impediment to liberalization.

While such problems could be ameliorated by placing very restrictive limits on the property-rights assigned to users (which could stymie a market's development), a more libertarian approach would seek to impose the lightest-touch regulations possible. From De Vany's point-of-view [15], the primary problem in designing a market system is not to decide whether an activity should be prohibited altogether or permitted as part of 
a right, but it is to define property rights so that it will be economically attractive to permit an activity as part of the right or to permit it if the consent of specified other parties is obtained. The right to engage with others with a view to change the activities permitted for a given piece of spectrum opens up the market to the possibility of arranging rights on a local basis to suit the local consumer needs and local spectrum actualities. A liquid market which allows for price discovery (which will certainly indicate the cost of dealing with interference effects for a given grade of spectrum), identification of opportunity cost and low-cost exchange of rights is a market that pools the knowledge and experience of many disparate and diverse actors in the field, actors bearing the costs of interference mitigation techniques, and efficiently shares that knowledge with others [16]. An account of the manner in which some De Vany-like rights are being introduced by regulators is presented in [17].

\section{Coasean Treatment of EXternalities}

Much of the discussion surrounding the liberalisation of spectrum, the use of auctions and the moves towards secondary markets owes its origins to Ronald Coase's 1959 paper on the F.C.C. [6]. In that paper Coase argued that spectrum was no different from any other resource. He argued that if it was seen to be in short-supply, or scarce, it should be allocated using a price mechanism. Drawing an analogy between Rembrandt's paintings and spectrum, he noted that 'despite all the efforts of art dealers, the numbers of Rembrandts existing at a given time is limited; yet such paintings are commonly disposed of at auction'.

In his 1960 paper [18], Coase extended some of the ideas he had presented the year previous. In his treatment of the problem of social cost, Coase turned the accepted methodologies on their head, loudly questioning the accepted wisdom of the approach now commonly named for Arthur Pigou [19]. His approach to the problem of social cost is not without its critics who decry an 'ideal system for a world that does not exist'. However, the world of dynamic spectrum access networks is one world in which the Coasean ideal of eliminating negative externalities through bargaining could be explored.

This section proceeds to briefly recapitulate the Coasean take on externalities, focusing on the notion of reciprocity of harm and identifying the least cost solution to the problem. The possible application of this approach to the problem domain of neighbouring exclusive spectrum-rights holders is then discussed.

\section{A. Reciprocity}

As noted in the previous section, many hold the view that the question of apportioning blame for the presence of negative externalities can be readily and fairly done through an analysis of the parties and actions involved, i.e. society can readily identify the victim and the violator and remedy the situation through tax or regulation. From such a standpoint, it is obvious when party A is harming party $\mathrm{B}$ when one bases ones judgement on socially accepted concepts and norms. Remedies are formed on the basis of restraining the actions of party A.

However, rather than assigning blame to one party or the other based on possibly arbitrary and unsubstantiated notions of harm, Coase asked question anew. He suggested that it was better to ascertain who whether party A should be allowed harm party B, or vice versa. From his point-of-view, the solution is to be found in avoiding the more serious harm. In his view, externalities are a joint product of the polluter and the victim and a legal rule that arbitrarily assigns blame to one of the parties only gives the right result if that party is the one that avoids the problem at lower cost.

\section{B. Crops versus Cattle}

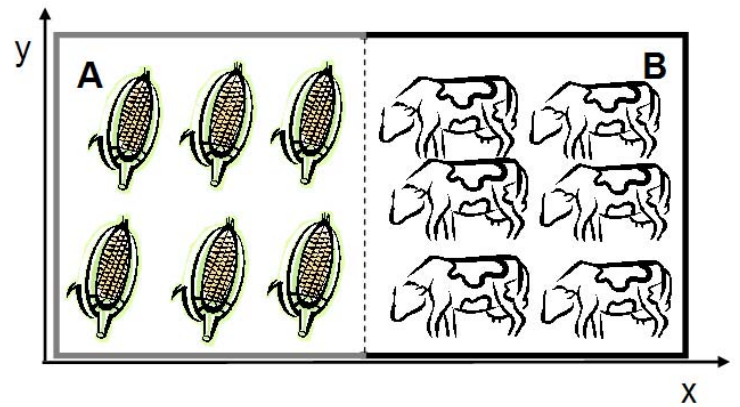

Fig. 1. Neighbouring Farmers, Different Land Uses.

To expediently elucidate his take on the general problem and its proposed solution, Coase explored the sample problem of conflicting uses of neighbouring farmland [18]. The original example is briefly introduced here before an analogous example from the spectrum domain is discussed. Figure 1 depicts two tracts of land owned by two different landowners; the owner of tract A grows crops, the owner of tract B raises cattle. Initially, the size of tract B is sufficient for the size of the herd and neither farmers' activities have negative consequences for the other. However, in the absence of a fence between the two farms, cattle will stray from tract B to tract A 
and destroy crops if more cattle are introduced to the herd by the owner of tract B, Figure 2 .

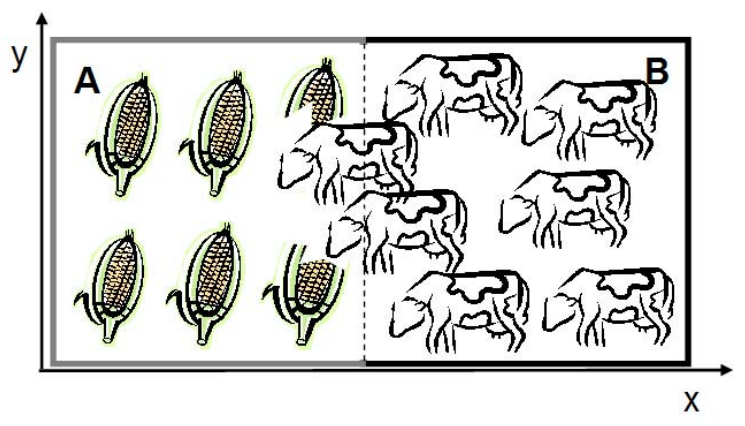

Fig. 2. An Increase in the Herd Size Leads to Crop Damage

The result is that there will be an increase in the supply of meat at the expense of a reduction in the supply of crops. As neither activity is innately more valuable than the other, in Coase's view, the choice as to whether the meat supply or the crop supply should be protected is not clear unless monetary values can be ascribed to each.

\section{Liability for Damage}

Coase suggested two solutions to the problem based on the making of bargains between the disputing parties, both of which presumed the existence of a smooth pricing system. Such a system would allow the parties to discover the values that each attaches to their land holdings and associated activities, e.g. cattle-raising or crop growing. Consequently, a pricing system is needed in order to arrive at a mutually satisfactory agreement a bargain. In the first scenario there was an assumption of liability for damage, in the second instance, there was an absence of such liability. The scenario involving an assumption of liability is our current focus as it tallies with the characteristics of a regime based on exclusive rights. In Section VI-C, a discussion of the scenario in which there is no assumption of liability is presented.

The crop/cattle problem manifests itself on the assumption that any increase in the cattle-raiser's herd will increase the total damage to the farmer's crops, as depicted in Figures 1 and 2. The original values, representing the assumed cost relationship between the activities of the neighbouring farmers are taken from [18] and presented in Table I. The crop farmer is able to fetch $\$ 1$ per ton for the crops on the market. Additionally, the cost of erecting a fence between tract A and tract B, which could be seen as a simple solution, is priced at \$9. Referring to Table I, in a system that assumes liability for damage caused, the cattle-raiser will incur an additional annual cost of $\$ 3$ if his herd is raised from two to three steers. So, the cattle-raiser will not increase the size of his herd unless the additional meat yields a value greater than the additional cost of liability. If the cattle-raiser were to increase his herd to four steers, then the additional cost through liability for damages would be $\$ 10$ - at this point, the cost of erecting the $\$ 9$ fence is better value then having to pay out damages.

TABLE I

Coase's Values for the Crop/Cattle Problem

\begin{tabular}{|l|l|l|}
\hline $\begin{array}{l}\text { No. in Herd } \\
\text { (Steers) }\end{array}$ & $\begin{array}{l}\text { Annual Crop } \\
\text { Loss (Tons) }\end{array}$ & $\begin{array}{l}\text { Crop Loss per } \\
\text { Additional Steer (Tons) }\end{array}$ \\
\hline 1 & 1 & 1 \\
2 & 3 & 2 \\
3 & 6 & 3 \\
4 & 10 & 4 \\
\hline
\end{tabular}

\section{The Fence as a Solution}

The construction of a fence to pen in the cattle removes the possibility of each parties' current activities from interfering with each other. However, were the cattle-raiser to switch to raising rabbits, then the fence might not suffice as they could burrow underneath it and possibly damage the crops. As such, the $\$ 9$ fence is only a solution to the current land uses. Nonetheless, for the stated uses of the land, the fence represents a fixed cost solution which either party may use if the costs are appropriate. Furthermore, such a solution can be unilaterally implemented in the absence of a mutually-agreed solution, on the assumption that the proposed solution is one that does not require another's permission.

\section{E. A Spectrum Example}

Turning to the problem domain of neighbouring exlcusive spectrum uses, a basic example is introduced. Consider the scenario in which two firms have acquired the spectrum rights for adjacent geographic areas, at the same frequency and for the same duration. More particularly, consider RuralNet Corporation which has acquired the TAS package ${ }^{1}$ covering tract $\mathrm{A}$ and CityConnect Corporation which has acquired the rights to tract B, as depicted in Figure 3. As both firms operate their respective networks on the same frequency band, this is the dimension in which conflict and harm may occur in this example. A discussion of the other

${ }^{1}$ A TAS package describes an exclusive package of spectrum rights in terms of time, space and frequency [15]. 
forms of conflict that may possibly arise is presented in Section VI. Furthermore, for the sake of simplicity in forming an arithmetic example, we assume the existence of a vertically separated industry in which both RuralNet Corp. and CityConnect Corp. operate simply as content-agnostic network operators whose sole function is to provide radio-based connectivity to the broader telecommunications infrastructure at varying levels of service. This simple and somewhat crude scenario is chosen so that an arithmetically-based solution similar to that originally proposed by Coase [18] can be presented. While the two spectrum rights holder in this example adapt the manner in which they access spectrum in response to bargaining processes, no explicit use of DSA techniques is explored in this section.

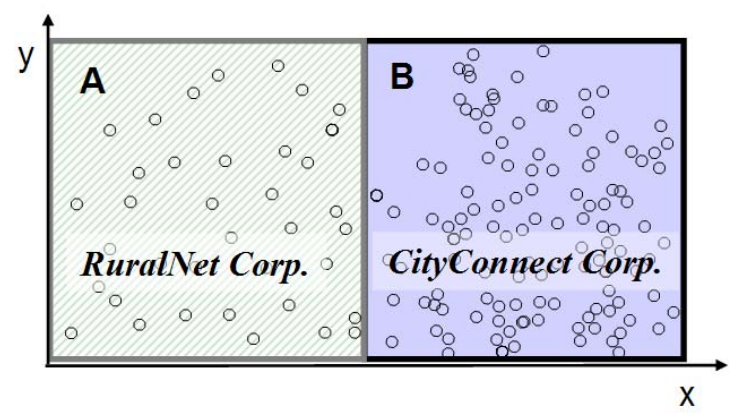

Fig. 3. Neighbouring Spectrum-Rights Holders, Different Spectrum Uses. Circles indicate population clusters.

The two TAS packages cover areas in which the population densities differ markedly. Tract A envelops a rural area with a low population density. Tract B envelops an urban area with a moderate population density. As illustrated in Figure 4, the respective owners of tract A and tract $\mathrm{B}$ have deployed differing systems to provide varying levels of connectivity and channel capacity in the areas to which they hold rights. RuralNet Corp. has deployed a single transceiver system and CityConnect Corp. has deployed a multiple cell system. As depicted in Figure 4, the two firms largely respect the terms of their TAS packages by ensuring that the power of their signals drop below the boundary limit at the boundary. However, as is evident in Figure 4, the service contour of CityConnect Corp.'s cell 3 extends beyond the $A-B$ boundary, i.e. the power of the cell 3 signal does not fall-off below the maximum level permitted at the boundary. Cell 3 interferes with the service area of Ruralnet Corp., either reducing the capacity in the area affected or eliminating coverage entirely. CityConnect Corp. is liable for the damage caused in this scenario under the terms of its TAS holding and would conventionally be viewed as the wrongdoer. However, from the Coasean point-of-view, the notion of greater damage should be determined by identifying which action more seriously inhibits the extraction of value from the resource.



Fig. 4. RuralNet Corp. (left) Uses a Single Cell Architecture, CityConnect Corp. (right) Uses a Multiple Transceiver Approach

The conflict in this example manifests itself on the basis that excessively powerful transmissions from within tract $\mathrm{B}$, which provide for an increased capacity in the area serviced by CityConnect Corp., will spillover into tract A and reduce the capacity of the service area of RuralNet Corp.'s operation. Such excessive transmission of power may occur for a number of reasons, both planned, e.g. to increase the cell capacity, and unplanned, e.g. the network planning process did not estimate the correct worst-case propagation footprint.

What ever the cause, any increase in power results in interference with RuralNet Corp.'s service area. In Figure 4 , cell 3 is transmitting at $2 \mathrm{~W}$, leading to interference in the adjacent TAS area. $500 \mathrm{~m}^{2}$ of RuralNet Corp.'s exclusive area can no longer connect to its network.

TABLE II

Sample Values for A Spectrum Problem

\begin{tabular}{|l|l|l|}
\hline $\begin{array}{l}\text { CityConnect Corp. } \\
\text { Cell 3 Tx. Power } \\
\text { (Watts) }\end{array}$ & $\begin{array}{l}\text { RuralNet Corp. } \\
\text { Service Area } \\
\text { Loss }\left(\mathrm{m}^{2}\right)\end{array}$ & $\begin{array}{l}\text { Additional RuralNet } \\
\text { Corp. Service Area } \\
\text { Loss per Cell 3 Tx. } \\
\text { Power Increment }\left(\mathrm{m}^{2}\right)\end{array}$ \\
\hline 1 & 0 & 0 \\
2 & 500 & 500 \\
4 & 1500 & 1000 \\
5 & 4000 & 2500 \\
6 & 5000 & 2000 \\
\hline
\end{tabular}

Following Coase's own example [18], a hypothetical cost relationship for the interactions of the neighbouring firms is presented in Table II. RuralNet Corp. normally expects to generate a profit of $\$ 20 / \mathrm{m}^{2}$ of serviced area. Additionally, it would cost $\$ 80,000$ for CityConnect 
Corp. to deploy an additional cell in the area such that two cells could provide the same service without causing damage to the neighbouring network, as depicted in Figure 4. CityConnect Corp.'s attempt to service its larger customer base, and consequent higher demand for connectivity and network capacity, has lead it to push the boundaries of its TAS by transmitting $2 \mathrm{~W}$ of power from the cell 3 transceiver. Referring to Table II, and continuing the assumption that the spectrum right holders are liable for the damage they cause, it may be seen that RuralNet Corp. has lost $500 \mathrm{~m}^{2}$ of its service area due to interference from CityConnect Corp. which will cost CityConnect Corp. $\$ 10,000\left(500 \mathrm{~m}^{2}\right.$ valued at \$20/month) in monthly payments for damages. CityConnect Corp. will pay the $\$ 10,000$ monthly fine so long as the profit it makes from having higher capacity in cell 3 is greater than this cost. If not, it has the option of reducing the transmission power of its cell 3 transmitter from $2 \mathrm{~W}$ to $1 \mathrm{~W}$, so that the power footprint of the cell would fall within the TAS area. However, this would lead to a decrease in its serviced area and cell capacity, culminating in a loss of revenue. There would be an overall loss in the value extracted from the combined activities of the two spectrum rights holders were it to reduce its service if it was generating any profit in excess of $\$ 10,000$.

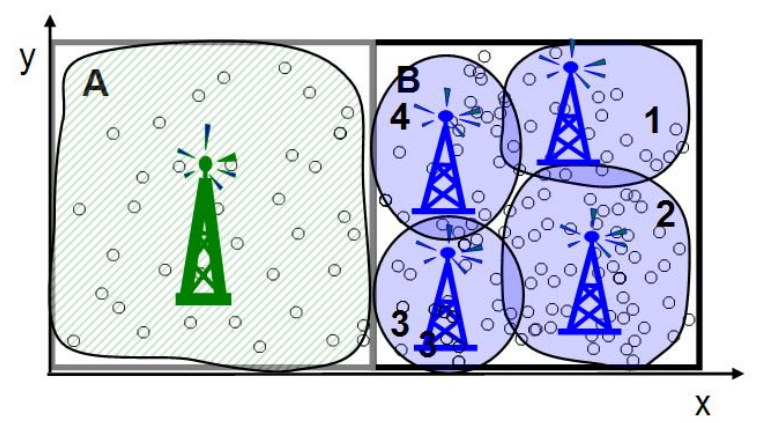

Fig. 5. Demographic Changes Impact Spectrum Demand at the Boundary

\section{F. An Incentive For Interference-Seeking Behaviour?}

Given that the CityConnect Corp. is liable for the loss of coverage and capacity in tract $\mathrm{A}$, it might seem to be advantageous for the RuralNet Corp., the rights holder for tract A, to maintain, or even increase, the level of service that it provides in tract A, subject to it respecting the boundary power limits. Since the rights holder for tract B is liable for the damage caused, the more damage inflicted on it, the more it would receive in payment for

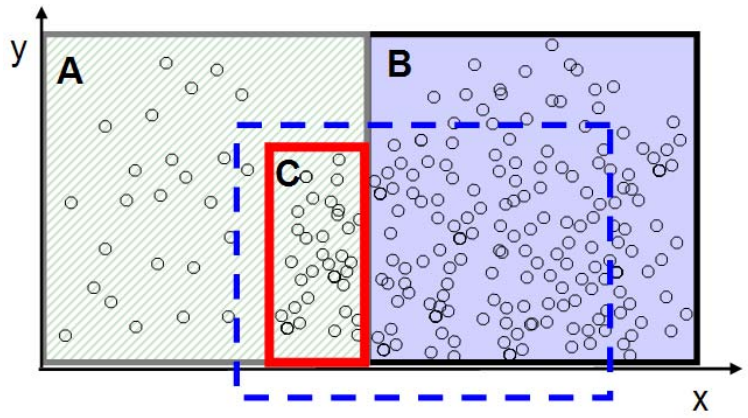

Fig. 6. Demographic Changes Impact Spectrum Demand at the Boundary

those damages. In other words, this system could suggest that it pays to be interfered with and consequently it pays to increase your sensitivity to such interference.



Fig. 7. The footprints the Cell 3 encroach on tract A

Coase's argument suggests that if CityConnect Corp.'s activities have any effect, they will be to reduce the area serviced by the RuralNet Corp.

Coase made this argument on the basis that for any given section of RuralNet Corp.'s holding, if the value of the service lost in that section through interference from CityConnect Corp. is great enough that the profits from the unaffected area are less than the total costs of servicing the area, it will be profitable for RuralNet Corp. to make a bargain whereby it discontinues servicing that area and attempting to derive gains from it.

Such an area is highlighted in Figure 6. The dashed rectangle highlights an area in which there has been population growth, the urban area is now more populous and there is more demand for network capacity. There has been much growth towards the $A-B$ boundary which CityConnect Corp. wishes to service. Using the existing cell 3 transmitter, CityConnect Corp. could adjust the transmission power to increase the capacity in this area. The power level options available to it are indicated in Table II. However, as depicted in Figure 7 and in 
Figure 8 , this approach leads to a further encroachment on tract A, diminishing the size of RuralNet Corp.'s serviced area. If CityConnect Corp. was to maximise the transmnission power at cell 3 to $6 \mathrm{~W}$, it would have a footprint that would encroach on a section of tract A which is identified in Figure 6 as tract C. Lets say that tract $\mathrm{C}$ covers an area of $5,000 \mathrm{~m}^{2}$.

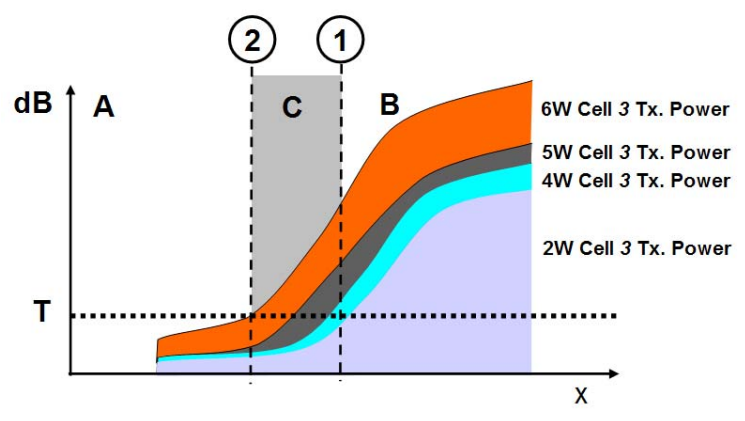

Fig. 8. Identification of a New TAS Boundary

Figure 8 shows that cell 3 violates the maximum power limit at the original $A-B$ boundary, marked 1 in the figure. The point at which the $6 \mathrm{~W}$ signal falls below the trespass level, marked $\mathrm{T}$ in Figure 8, suggests that a new boundary could be situated at the point marked 2 in the figure. Thus the footprint of cell 3's 6W signal helps to define the possible extent of tract $\mathrm{C}$.

The cost to RuralNet Corp. of servicing tract $\mathrm{C}$ is $\$ 50,000$ a month. Say this is made up of $\$ 25,000$ a month for the cost of a sectoral antenna that services tract $\mathrm{C}$ and another $\$ 25,000$ which is the proportional monthly cost of acquiring this section of tract A. Given that it costs $\$ 50,000$ per month to operate a network in tract $\mathrm{C}$ and it has a potential monthly turnover of $\$ 150,000$ (i.e. $\$ 30 / \mathrm{m}^{2}$ per month assuming that the revenue would be generated evenly across the tract (and also initially assuming no interference from CityConnect Corp.), the net gain would be $\$ 100,000$ per month, i.e. a profit of $\$ 20 / \mathrm{m}^{2}$ per month. However, when the CityConnect Corp.'s cell 3 interferes with tract $\mathrm{C}$, it results in the serviceable area being reduced by $500 \mathrm{~m}^{2}$, which in turn affects the turnover of RuralNet Corp. for tract C. So RuralNet Corp. only generates a turnover of $\$ 135,000$ based on the remaining $4,500 \mathrm{~m}^{2}$ and receives damages for the $500 \mathrm{~m}^{2}$ of area that it is unable to service in the amount of $\$ 15,000$, still resulting in a net gain of $\$ 100,000$.

If CityConnect Corp., finding it profitable, increases its transmission power in cell 3 to $5 \mathrm{~W}$ such that it eliminates coverage in $4000 \mathrm{~m}^{2}$ of the service area in tract C, RuralNet Corp. stands to lose $\$ 120,000$ in gross revenue. However, the net profit that RuralNet Corp. would gain from tract $\mathrm{C}$ would stil stand at $\$ 100,000$ as it will make $\$ 30,000$ on the untouched $1000 \mathrm{~m}^{2}$ of tract C and collect $\$ 120,000$ damages from CityConnect Corp., which after costs of $\$ 50,000$ leaves it with $\$ 100,000$. So, even though RuralNet Corp. can only ever make $\$ 100,000$ profit from tract $C$ using the technology it has deployed and given the population in its service area, there comes a stage when CityConnect Corp. is losing more in damage payments than the RuralNet Corp. expects to make in profits from the existing set-up.

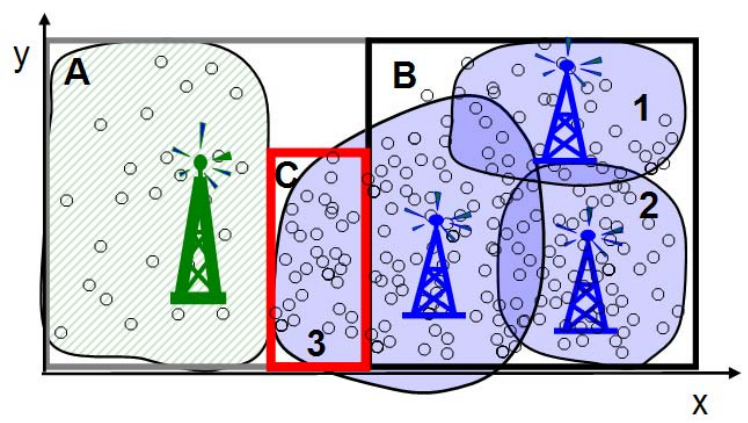

Fig. 9. Amending Rights in Favour of Greater Value Extraction

Coase's theory suggests that CityConnect Corp. would be better off if RuralNet Corp. would agree to abandon servicing tract $\mathrm{C}$ for any price less than $\$ 120,000$. Likewise, RuralNet Corp., who can only make $\$ 100,000$ through its current set-up, would be better off if it would agree to this arrangement for any price greater than $\$ 100,000$. Somewhere between $\$ 100,000$ and $\$ 120,000$ lies a price for the exchange of rights to tract $\mathrm{C}$ which would benefit both parties and eliminate the existence of that negative externality. The result of such a bargain is shown in Figure 9 in which CityConnect Corp. has the right to the TAS package covering tract $\mathrm{B}$ and tract $\mathrm{C}$.

This same argument would hold for various subdivisions of the tract A. Furthermore, there may be other palatable arrangements such as the RuralNet Corp. switching to a technology that was less liable to interference by CityConnect Corp. activities, but which would not be as profitable as the former technology (if deployed in the absence of interference).

The examples presented in this section only touch on the variety of bargains that could be arrived at in a system where such pricing information as shown in Tables I and II was available and all of the participants followed rational courses of action which attempted to maximise their individual profits. However, more discussion of the 
effects of such bargaining is necessary, most specifically on the effects that such bargaining may have on the pricing and sale of the original TAS packages. In short, such bargaining should lead to a grading of the resource in the long-term such that rights holders who extract similar values from their resources should cluster.

\section{CoAseAn CRITICISMS}

Criticism has come from a number of sources, not least from the camp of adherents to the stance both advocated and well-documented by Arthur Pigou [19]. "This paper is concerned with those actions of business firms which have harmful effects on others." [18]. Coase was very particular in noting that he wanted to discuss the problem of social cost in terms of firms. Firms, he noted in his response [20] to A.W. Brian Simpson's critique [21] of the 1960 work [18], are the particular actors that he considers to be relevant to the problem. Such clarification as to the subject of his exploration of the problem of social cost was necessary as Coase's use of the Sturges v. Bridgman example (i.e. the case of two quarreling neighbours, a doctor and confectioner) in his F.C.C. paper the year before [6], has been used in subsequent literature and debate in an effort to diminish the fundamental contributions of his work. It is argued that his proposed remedies would not withstand the vagaries of bargaining humans and the peculiarities of their individual personalities. More particulary, Coase clarified that he was discussing firms which 'will normally be attempting to maximise their profits and the etiquette governing the relations of neighbours would have little relevance for their behaviour' [20].

The Pigouvian camp also criticise the very notion of looking at harm as a joint or reciprocal concept, seeing it as anathematic to of very notion of society. It is argued [21] that one cannot simply turn conventionally received notions of harm, of victim and of polluter on their head. However, this argument regarding the notion of society, and its conventional expectations, is largely moot in the context of a liberal environment of spectrum trading and markets and exclusive rights. In that context, assuming that government will never surrender all of the spectrum to market forces, a portion of spectrum will be held back precisely because the Pigouvian argument will hold sway to some degree. In the minds of many, socially beneficial services such as public service television and public safety communications services are not suited a market-based regime.

Such is the fervour illicited by the Coasean approach, that it is suggested in [21] that the mutual suicide of the neighbouring Dr. Sturges and confectioner Mr. Bridgman would qualify as a Coasean bargain. It would not. It would be akin to a decision by both CityConnect Corp. and RuralNet Corp. to simultaneously and permanently cease all activities in their respective TAS packages. To suggest this is to be mischievous and to miss the point. A Coasean bargain should allow parties to arrive at a Pareto optimal solution when there is a Pareto relevant externality present. When the externality is Pareto irrelevant, then Pigou's approach is called for.

\section{DSA ANSWERS}

The arguments in Section III were presented on the basis that the pricing system was smooth, i.e. that there were no transaction costs. This is an obviously unrealistic assumption. Transaction costs can be seen as a necessary condition for the persistence of externalities, for with zero transaction costs (and an enabling framework of rights, discussed in [8]) the effects will be internalized [22]. In terms of the Coasean bargaining process, transaction costs have been identified under the following headings:

1) Search: each party needs to find the other party

2) Convey: each party needs to inform the other as the presence of an exchange opportunity

3) Decision: if it is a multilateral process, i.e. several agents on each side, then several extra layers of decision-making have to take place

4) Policy \& Monitoring: the terms of the bargain are enforced

In entering a bargaining process to remedy the effects of interference and balance its existence along a common boundary in favour of maximal value, the parties to such a process need to be in possession of their own production and utility costs. While the values that were presented in Tables I and II were plucked from the ether, a real DSA-based scenario will require DSA firms to acquire accurate pricing information at minimal cost. A competitive secondary (or after) market enables participants to discover the price of raw spectrum at the required grade. However, within each spectrum holding, acquired on such a market, the value that the licensee can extract from that spectrum holding is dependent on its use of technology, i.e. how well it can mine its resource, and the consumer demand for its offering. Solutions have been offered for the dynamic internal pricing of bands of spectrum, such that the use of that particular band of spectrum is maximised with regard to the demand placed on it by its end-users [23], [24]. The notion of a spectrum broker, which manages the allocation of 
spectrum according to price in cellular networks, has been presented as a model which can maximise the value extracted from a licensed band of spectrum [24]. The QinetiQ Sky Dust ${ }^{T M}$ [23] system enables a licensee to manage the internal trading of its spectrum holding according to the varying demand of its customers. Unlike the system described in [24], the QinetiQ framework offers a solution for such internal price discovery in peerto-peer network architectures.

Presently, the secondary market is one that consists of notification to the regulators, approval or denial of requests to trade and the transfer of ownership of physical assets (e.g. network infrastructure) when a trade occurs. Even though some of it is built around e-licenses, i.e. the Internet is used as a means to file claims with the F.C.C. et al., the process still involves humans sitting at desks making decisions. The intervals at which such trades occur is likely to be of the order of six to twelve months considering the expense of expanding or downsizing a telecommunications company. In moving to DSA-enabled environment, and focussing on DSA as a means to remedy interference issues, the notion of. Mechanisms for searching, conveying, deciding and then enforcing and monitoring policy have already received much attention and many are suited to the application for the modalities of a bargaining scheme.

There is a wealth of research in the area of distributed, pervasive, mobile, and wireless computing which has yielded any number of possible solutions to issues such as dynamic policy enforcement, dynamic authorization, dynamic authentication and trust schemes [25]-[30], general security services, dynamic payment and settlement techniques [31], [32], among others. That these technologies have been motivated by Primary/Secondary and Secondary/Secondary (i.e. peer-to-peer) relationships does not preclude their application to this environment; quite the opposite in fact. The peer-to-peer communications environment assumes more extreme (i.e. worse) conditions of trust and behaviour than conventional network systems do. Protocols and services designed for such demanding characteristics should prove robust to the challenges of licensee-to-licensee interaction.

Dahlman [22] also presents the concept of transaction costs as manifesting themselves in the following two forms:

1) Proportional Costs: a proportion of whatever is being traded is assumed to disappear in the transaction itself.

2) Fixed Costs: while a trade may be costless to carry through, it may still require resources to organise,

\section{i.e. set-up costs}

The issue of organisation and re-organisation is innate to a DSA network. As noted in the Introduction, the realisation of DSA networks implies an ability on the part of radio devices to sense others' waveforms and adapt their own. This ability to adapt and reconfigure extends from the physical-layer right up to the application-layer of the communication protocol stack. But most importantly, from the point-of-view of re-organising on account of interference agreements, the reconfigurable and software radio paradigms that form the basis of much of the DSA developments focus specifically on addressing interference issues. Bose [33] describes the advances in the components that from the building-blocks of software radio architectures, which will increasingly move from hardware to software, greatly increasing the range of options available to a radio to deal with both adjacent and co-channel interference management. In essence, such advances will enable a radio, for whatever motivation, e.g. opportunistic purposes or economically motivated bargains, to optimally organise itself according to its prevailing utility function.

\section{LOCAL DSA BARGAINING}

Given a combination of De Vany-like flexible rights, DSA technology and rational profit-seeking firms competing in a market, there are a number of ways in which these three elements could combine to deal with presence of interference-related externalities. As discussed, Coasean bargaining with regard to interference is about finding a balance between enforcing the removal of interference-causing signals, an action which may lead to underutilised spectrum at the boundaries of rights, and tilting the scales in favour of allowing the more productive use of spectrum - which, absent of an agreement, would be illegal encroachment. This section briefly considers some Primary/Primary interactions and possible mutually satisfactory arrangements that could be arrived at given the foregoing assumptions.

\section{A. Coasean easements}

As discussed in Section III-E, any rational spectrum rights holder should provide an easement to a neighbouring rights holder on terms that are more beneficial to him that were he not to give an easement. So, in the case of two adjacent channel neighbours, as illustrated in Figure 10, it can be seen that at this time Primary B is not using the full bandwidth of its spectrum. As activity in Primary A's band increases, it dynamically expands its transmission masks and filters to accommodate the 
demand for service, Figure 11. This may lead to some adjacent channel interference and adjacent channel signal rejection by either Primary A or Primary B - but Primary $\mathrm{A}$ is liable for this interference.

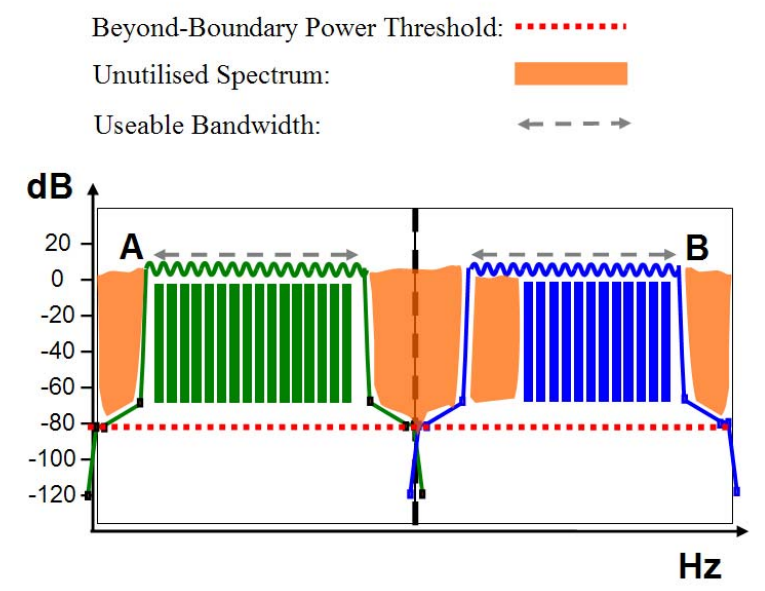

Fig. 10. Adjacent Channel Neighbours

Since Primary B is not at capacity, it pays for it to strike a deal with Primary A in which it receives payment to reduce its frequency footprint such that both parties suffer less adjacent channel interference and a Pareto optimal arrangement is adopted.

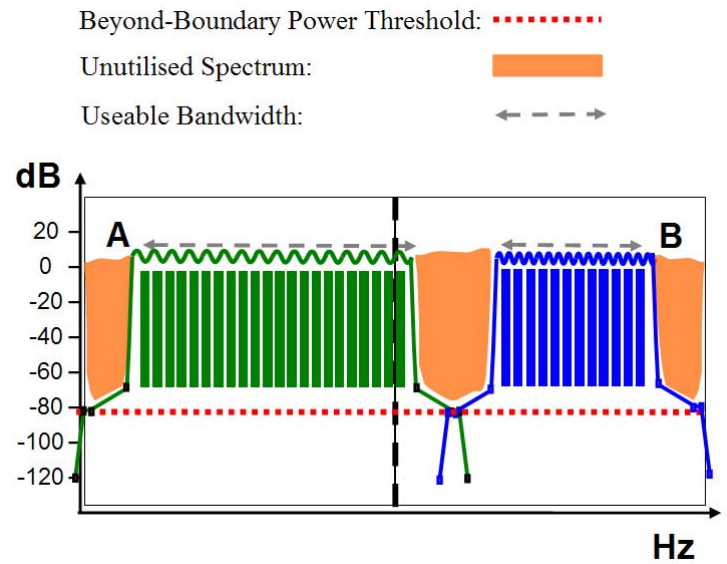

Fig. 11. Adjacent Channel Easement

\section{B. Coasean commons}

When the resolution of the problem of social cost is too complex for a DSA network to organise through bargaining, another option arises. In some scenarios it may be beneficial to combine two resources under a common ownership (or common leasing), i.e. a single firm, such that the organisation of the resources is carried out administratively. In terms of combined spectrum rights this amounts to the agreement on a technical etiquette which would optimise the use of the joint resources [34]. Such an agreement would still involve the payment from one side to the other to strike the bargain. Under such an arrangement, the negative effects of the interference is managed by either treating the contiguous areas or contiguous bands of spectrum as single entities to be managed by a common MAC.

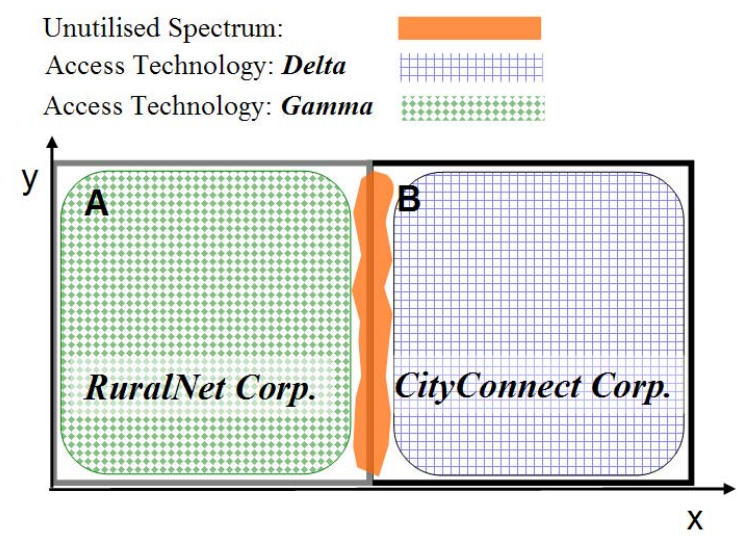

Fig. 12. Individual Spatial Property Rights, Separate Access Regimes.

Figure 12 depicts adjacent rights holders - they share a common area boundary and are susceptible to co-channel interference. The orange patch between the two networks indicates whitespace which has been created by the each party withdrawing from the boundary to comply with requirements of their licence. So, for each rights holder, the anticipation of causing interference has caused them to reduce the capacity of their respective networks. A Pareto optimal solution to this problem could be to manage the interference at the medium access control (MAC) level of the network rather than at the physical layer. Such an agreement would require the selection of a common MAC etiquette (the Kappa MAC) which would treat the spectrum in that area as a single holding and apportion the bandwidth to the respective rights holders according to their agreement. The ability to make an arrangement such as dynamically combining geographic areas is dependent on DSA technologies (reconfigurable radios, software radios) to enable organisation of such a disaggregated network architecture where.

Of course such an approach is also viable for the case in which the two rights holders share an adjacent boundary in the frequency dimension. In such a case the two parties could bond their frequency assignment and allocate the shared frequency in the form channels using 


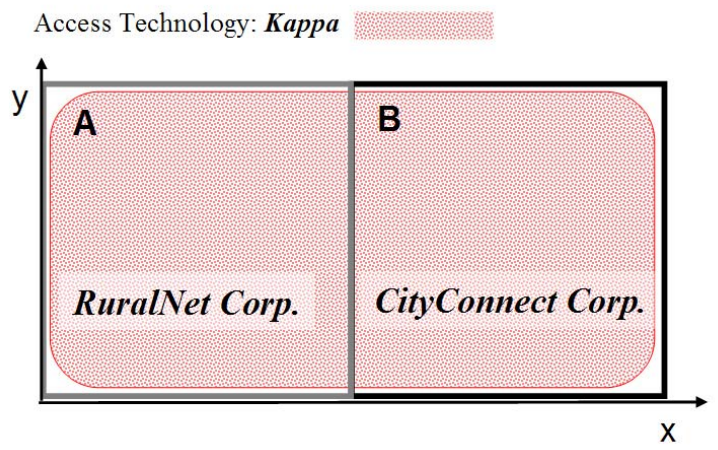

Fig. 13. Individual Property Rights, Common Access Regime.

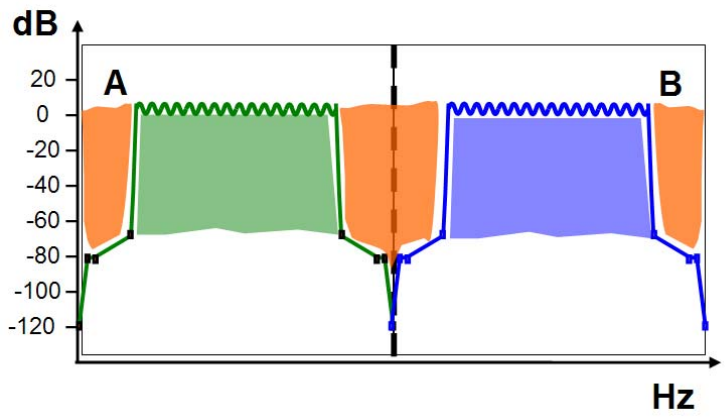

Fig. 14. Individual Frequency Property Rights, Separate Access Regimes.

a common MAC, as illustrated in Figures 14 and 15.



Fig. 15. Individual Frequency Property Rights, Common Access Regime.

\section{Bargaining for Opportunistic Access}

Furthermore, while the main focus of the paper has been on the use of Coasean bargaining to remove the presence of externalities in a libertarian system of exclusive spectrum rights through the creation of various economically motivated easements, there is also scope for Coasean bargaining towards Pareto optimal allocations of spectrum in the area of opportunistic spectrum access.
The opportunistic use of spectrum occurs when a spectrum user exploits spare capacity at a given frequency, space and time to which it does not have exclusive rights. In the case of opportunistic overlay, users sense when the primary user is not using its exclusive spectrum TAS and sneak in to exploit the spectrum whitespace. These users have no rights to the whitespace and must release it when the primary user returns. In the case of opportunistic underlay, users exploit any space between the accepted noise floor level and the actual noise at a particular frequency, space and time. Since a user cannot be held liable for trespass below the accepted noise floor, a liveand-let-live approach is adopted. In both the underlay and overlay situations, opportunistic users are not liable for damage they may cause to other opportunistic users since no exclusive rights prevail. However, there is a possibility that neighbouring opportunistic users can also form Coasean bargains so that Pareto optimal use of the whitespace spectrum is made.

In this scenario, the damaging user does not have to make payments to those damaged by its actions. However, Coase suggests that the allocation of resources will be the same as in the case with liability. In this case, the party suffering damage would be willing to pay the party causing damage if it would reduce or eliminate the causes of that damage. Coase argues that any refused offer must be considered revenue foregone, and must be considered when deciding to operate in a manner that still causes damage to the party. This rejected offer is equivalent to the damages that the user would have had to pay the under a system of liability - in either case it is a cost associated with activities causing negative effects - damage. In a similar vein to the example presented in Section III, it can be shown that a system without liability could work equivalently to a system assuming liability.

\section{CONCLUSIONS}

As the regulators step back from the position of allocating and managing blocks of spectrum so as decide and enforce the appropriate arrangement of uses of the radio spectrum, it will be left to the spectrum rights holders to organise themselves through the market. Interference is often held up as one of the primary factors standing in the way of creating very liquid, competitive market for exclusive spectrum usage rights. It is argued that the spillover effects of radio waves will not allow rights holders to adequately enforce their rights so as to extract full value from their holdings. 
However, in this paper we have argued that the advent of dynamic spectrum access technologies offers an alternative solution to the unilateral enforcement approach which characterises the parties in terms of victim and violator. Coasean bargaining may offer a means of mutually remedying and finessing the interference issues that will inevitably arise along the shared boundaries of spectrum rights holders. The local manifestations of fundamental electro-magnetic phenomenoma vary in such a way that they cannot be captured in a market which aims to standardise the instruments of trade so as to promote liquidity and price discovery. Rather, local and dynamic Coasean bargains could provide an alternative approach to smooth the interference wrinkles which will inevitably arise. In fact the Coasean approach diminishes interference-seeking behaviour III-F.

The technologies that form the basis for DSA networks lower the costs of sensing waveforms, shaping waveforms and dynamically reorganising the structure of the network. Consequently, such advances reduce the transaction costs associated with arriving at mutually satisfactory interference management arrangements. Indeed, DSA networks, coupled with the array of protocols and services that have already been designed for policy enforcement, security, trust, payment issues in the challenging peer-to-peer and distributed networking environment, provide a means to maximise the level of tolerable interference between rights holders - a balance that indicates the market-assigned spectrum is being put to its most productive use.

\section{ACKNOWLEDGEMENT}

This material is based upon works supported by Science Foundation Ireland under Grant No. 03/CE3/I405.

\section{REFERENCES}

[1] X. Liu and W. Wang, "On the characteristics of spectrum-agile communications networks," in Proc. First IEEE International Symposium on New Frontiers in Dynamic Spectrum Access Networks. (DySPAN 2005), Baltimore, Maryland, U.S.A., November 2005 , pp. $214-223$.

[2] W. Gardner and C. Spooner, "Signal interception: performance advantages of cyclic-feature detectors," IEEE Transactions on Communications, vol. 40, no. 1, pp. 149-159, 1992.

[3] N. Shankar Sai, C. Cordeiro, and K. Challapali, "Spectrum agile radios: utilization and sensing architectures," in Proceedings of the First IEEE International Symposium on New Frontiers in Dynamic Spectrum Access Networks. DySPAN 2005., pp. 160 - 169, November 2005.

[4] "Second Report and Order, Order on Reconsideration, and Second Further Notice of Proposed Rulemaking (FCC 04167):Promoting Efficient Use of Spectrum Through Elimination of Barriers to the Development to Secondary Markets," Federal Communications Commission, September 2004.
[5] R. McAdoo, P. Argyroudis, L. Doyle, and D. O'Mahony, "Arhcitectures for Person to Person Communications in Disaggregated Networks," to appear in Proceedings of the IEEE International Conference on Digital Telecommunications (ICDT 2006), 2006.

[6] R. Coase, "The Federal Communications Commission," Journal of Law and Economics, vol. 2, pp. 1-40, October 1959.

[7] A. S. De Vany, "Implementing a Market-Based Spectrum Policy," Journal of Law and Economics, vol. 41, no. 2, Oct 1998.

[8] L. E. Doyle and T. K. Forde, "Towards a Fluid Spectrum Market for Exclusive Usage Rights," in Proc. IEEE International Symposium on New Frontiers in Dynamic Spectrum Access Networks. (DySPAN 2007), Dublin, Ireland., April 2007.

[9] W. Webb, "The Role of Economic techniques in Spectrum Management," IEEE Communications Magazine, vol. 4, no. 3, March 1998.

[10] T. Hazlett, "The Spectrum-Allocation Debate: An Analysis," IEEE Internet Computing, vol. 10, no. 5, Sept-Oct 2006.

[11] M. McHenry and D. McClosky, "New York City Spectrum Occupancy Measurements September 2004," Shared Spectrum Company, www.sharedspectrum.com.

[12] D. N. Hatfield and P. J. Weiser, "Property rights in spectrum: Taking the next step," Proceedings of the First IEEE Symposium on New Frontiers in Dynamic Spectrum Access Networks, pp. 43-55, November 2005.

[13] E. Kwerel and J. Williams, "A Proposal for a Rapid Transition to Market Allocation of Spectrum," Office of Plans and Policy, Federal Communications Commission, no. 38, November 2002.

[14] W. H. Melody, "Radio Spectrum Allocation: Role of the Market," The American Economic Review: Papers and Proceedings of the Ninety-Second Annual Meeting of the American Economic Association., vol. 70, no. 2, May 1980.

[15] A. S. De Vany, R. D. Eckert, C. J. Meyers, D. J. O’Hara, and R. C. Scott, "A Property System for Market Allocation of the Electomagnetic Spectrum: A Legal-Economic-Engineering Study," Stanford Law Review, vol. 21, no. 6, June 1969.

[16] J. Surowiecki, "The wisdom of crowds: why the many are smarter than the few," 2004.

[17] R. Ercole, "Innovation, spectrum regulation, and DySPAN technologies access to markets," Proceedings of the First IEEE Symposium on New Frontiers in Dynamic Spectrum Access Networks, pp. 494- 511, November 2005.

[18] R. Coase, "The Problem of Social Cost," Journal of Law and Economics, vol. 3, pp. 1-44, October 1960.

[19] A. Pigou, The Economics of Welfare (4th Ed.). Macmillan, 1960.

[20] R. Coase, "Law and Economics and A. W. Brian Simpson," The Journal of Legal Studies, vol. 25, no. 1, Jan 1996.

[21] A. Brian Simpson, "'Coase v. Pigou" Reexamined," The Journal of Legal Studies, vol. 25, no. 1, Jan 1996.

[22] C. Dahlman, "The Problem of Externality," Journal of Law and Economics, vol. 22, no. 1, pp. 141-162, 1979.

[23] D. Robinson, A. Shukla, J. Burns, and A. Atefi, "Resource trading for spectrum aggregation and management," Proceedings of the First IEEE Symposium on New Frontiers in Dynamic Spectrum Access Networks, pp. 666- 671, November 2005.

[24] M. Buddhikot and K. Ryan, "Spectrum management in coordinated dynamic spectrum access based cellular networks," Proceedings of the First IEEE Symposium on New Frontiers in Dynamic Spectrum Access Networks, pp. 299- 307, November 2005.

[25] P. Argyroudis and D. O'Mahony, "Towards flexible authorization management," in Proceedings of the 10th IEEE Symposium 
on Computers and Communications.(ISCC 2005), pp. 421-426, 2005.

[26] D. Lewis, K. Feeney, and D. O'Sullivan, "Integrating the policy dialectic into dynamic spectrum management," in Proc. IEEE International Symposium on New Frontiers in Dynamic Spectrum Access Networks. (DySPAN 2007), Dublin, Ireland., April 2007.

[27] J. Poston, W. Horne, M. Taylor, and F. Zhu, "ntology-Based Reasoning for Context-Aware Radios: Insights and Findings from Prototype Development," Proceedings of the First IEEE Symposium on New Frontiers in Dynamic Spectrum Access Networks, pp. 634- 637, November 2005.

[28] M. Blaze, J. Feigenbaum, J. Ioannidis, and A. D. Keromytis, "The keynote trust-management system, version 2," Network Working Group, Request For Comments (RFC) 2704, September 1999.

[29] D. Ferraiolo and D. Kuhn, "Role-based access controls," in Proceedings of NIST-NSA National Computer Security Conference, pp. 554-563, 1992.

[30] M. Blaze, J. Feigenbaum, and J. Lacy, "Decentralized trust management," IEEE Conference on Security and Privacy, May 1996.

[31] F. Stajano and R. Anderson, "The resurrecting duckling: Security issues for ad hoc wireless networks," in Proceedings of 7th International Workshop on Security Protocols, pp. 172-182, 2000.

[32] D. Balfanz and D. Smetters, "Talking to strangers: Authentication in ad hoc wireless networks," in Proceedings of 9th Network and Distributed System Security Symposium(NDSS'02), pp. 172-182, 2002.

[33] V. Bose, "Opportunities and challenges in software radio design for interference management," Int. J. Netw. Manag., vol. 16, no. 2, pp. 149-156, 2006.

[34] R. H. Coase, "The Nature of the Firm," Economica, New Series, vol. 4, no. 16, Nov 1937. 